\title{
A tailshock-restraint technique for acute induction of gastric lesions in rats
}

\author{
MICHAEL N. GUILE and N. BRUCE McCUTCHEON \\ State University of New York at Albany, Albany, New York 12222
}

\begin{abstract}
A procedure using tailshock plus body restraint is described for the rapid induction $(6 \mathrm{~h})$ of glandular stomach lesions in the rat. In a group of 50 rats, a $92 \%$ ulceration rate was achieved.
\end{abstract}

Frequently, either immobility or electric grid shock have been used to induce glandular stomach ulcers in animal subjects. Immobility methods (e.g., Brodie \& Hanson, 1960) typically involve long sessions (often $24 \mathrm{~h}$ or longer) and low percentages of subjects showing lesions. Electric grid shock methods (e.g., Wald, MacKinnon, \& Desiderato, 1973) suffer from the inherent variability and lack of control of shock intensity as a result of motor activity or postures adopted by animals. Tailshock combined with whole-body restraint provides greater control over shock delivery and results in more reliable and rapid ulcer induction. The method described was originally devised to study the effects of electrical stimulation of the brain on gastric pathology (McCutcheon \& Guile, Note 1), but it is amenable to many experimental designs.

\section{CONSTRUCTION}

The materials needed for the construction of the neck-restraint tubes are transparent Plexiglas tubing (outside diameter of 2.25 in., inside diameter of 2 in.), Sears rubber mack gaskets (D42 M2259; outside diameter of 2 in., inside diameter of 1.25 in.), epoxy cement, 2 -in.-wide duct tape, .25-in. hardware cloth mesh, and .25 -in.-diam plastic dowels. To construct one tube, saw off a 14-cm section of the Plexiglas tubing. With a 4-mm bit, drill a series of holes spaced $2 \mathrm{~cm}$ apart around the circumference of the cylinder about $6.7 \mathrm{~cm}$ from the end of the tubing. These holes are for air circulation and intraperitoneal injections. The mack gaskets are epoxied (plug side out) to the end of the tube closest to the ring of drilled holes; the lip is flush with the end of the cylinder (if an experiment requires a skull-mounted electrode or cannula, a $1 . \mathrm{cm}$ piece of the gasket can be removed prior to cementing to allow room for the head

This research was supported by Grant AM 19673-02 from the National Institute of Arthritis, Metabolism, and Digestive Diseases. The authors thank Scott Nelson for help in collecting data. Address reprint requests and other inquiries to either Michael Guile or Bruce McCutcheon, Department of Psychology, State University of New York at Albany, 1400 Washington Avenue, Albany, New York 12222.

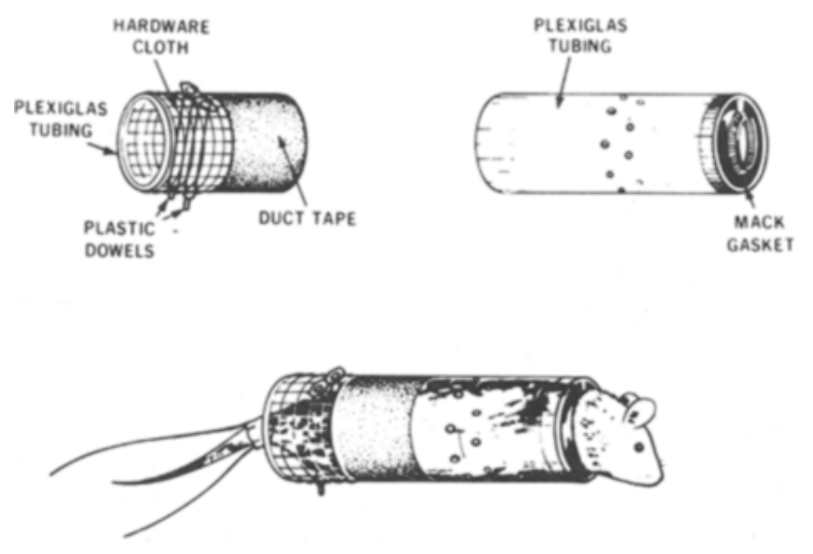

Figure 1. Neck-restraint tube apparatus for the acute induction of glandular stomach lesions in rats.

to push through the gasket). This completes the front half of the restraint assembly.

To build the rear assembly, cut a $10 \times 23 \mathrm{~cm}$ piece of hardware cloth and saw off a second $3.5-\mathrm{cm}$ section of tubing. Cut two 8-cm-long dowels (we used disposable 1-cc tuberculin syringe barrels). Bend and form the hardware cloth into a cylinder $10 \mathrm{~cm}$ long with a diameter of $6 \mathrm{~cm}$ (to fit over the front assembly). The ends of the hardware cloth should overlap by about $5 \mathrm{~cm}$. Wrap the duct tape about one end of the hardware-cloth cylinder to keep its shape. About $1 \mathrm{~cm}$ behind the end of the tape, insert the two plastic dowels (parallel, about $1.5 \mathrm{~cm}$ apart) through the hardware cloth and out the other side. These two dowels prevent the animal from backing out of the tube. Insert the short piece of Plexiglas tubing behind the dowels inside the mesh cylinder (to keep the tail and feet from tearing on the hardware cloth) and epoxy them together in place. This completes the second half of the restraint assembly. A labeled diagram of the apparatus is shown in Figure 1. The apparatus with the described Plexiglas tubing works on adult rats weighing up to $350 \mathrm{~g}$.

\section{METHOD}

To restrain a rat, quickly pick up the animal by the base of the tail and insert it nose first into the front part of the restraint 
assembly. Usually, the rats will scoot into the assembly. When the animal's head is through the gasket, bring up the rear assembly, being careful to position the rat's tail between the two dowels so that it trails out the end. A long piece of duct tape holds the front and rear assemblies together. With the subject so restrained, head and tail sticking out, the tail is cleaned with an alcohol swab and the tail electrodes are affixed about $4 \mathrm{~mm}$ apart, $3 \mathrm{~cm}$ from the base of the tail. The electrodes must be carefully attached with adhesive tape so that they will not shift with gentle tugging. They should be snug enough for good contact, but not so tight as to substantially restrict blood flow. Fuse clip electrodes are satisfactory, because they can be adjusted easily to provide a firm but nondamaging fit to the individual tail diameter.

\section{RESULTS}

Our 48-h food-deprived rats were subjected to a 6 -h session of constant-current (ac), 3-mA, 1-sec unsignaled tailshocks delivered on a variable-time $45-\mathrm{sec}$ schedule. Electric shocks were generated by a Lafayette Instrument Company constant-current ac shocker (Model 82400) and applied through fuse clip electrodes. A total of 480 shocks were delivered over the $6 \mathrm{~h}$. Animals were run in squads of three hooked in series to the shock generator. After $6 \mathrm{~h}$ the rats were sacrificed with sodium pentobarbital. The stomachs were removed and scored when fresh for number and cumulative length of discrete, coagulated blood-filled glandular lesions by viewing under a binocular dissecting microscope (at
$15 \mathrm{X}$ ). Of these subjects, $92 \%$ (46 out of 50 ) had at least one glandular stomach erosion (range $=0-40$ ). The median lesion count was 8.5 (mean $=10.4, \mathrm{SD}=8.2$ ). For the measure of cumulative lesion length, the range was from $0 \mathrm{~mm}$ to $55.4 \mathrm{~mm}$. The median cumulative length was $5.6 \mathrm{~mm}$ (mean $=8.5 \mathrm{~mm}, \mathrm{SD}=9.7 \mathrm{~mm})$. The animals had a mean weight loss of $4.9 \mathrm{~g}$ (SD $=$ $2.2 \mathrm{~g}$ ). Lesion count and cumulative lesion length were significantly and positively correlated $[\mathrm{r}(48)=+.79$, $\mathrm{p}<.01]$. Weight loss was not significantly correlated with either measure of gastric pathology.

\section{REFERENCE NOTE}

1. McCutcheon, N. B., \& Guile, M. N. ESB reduction of shockrestraint induced gastric lesions in rats. Paper presented at the meeting of the Eastern Psychological Association, Hartford, Connecticut, April 1980.

\section{REFERENCES}

Brodie, D. A., \& Hanson, H. A study of the factors involved in the production of gastric ulcers by the restraint technique. Gastroenterology, 1960, 38, 353-360.

Wald, E. D., MacKinnon, J. R., \& Desiderato, O. Production of gastric ulcers in the unrestrained rat. Physiology \& Behavior, 1973, 10, 825-827.

(Received for publication February 29, 1980; revision accepted May 12,1980 .) 